not have been discovered if the use of dogs had been prohibited.

Though the advances in medicine of recent years have been so marked, much remains to be discovered. If this Bill is allowed to become law, all research in this country into such problems as the causes and treatment of diabetes, of Bright's disease, of heart disease, of dropsy, of disorders of the stomach and intestines, and many others, will be hampered to such an extent that progress in our knowledge will come to an end, except in so far as it can be attained by observations and experiments on human patients themselves.

A prohibition of the use of $\operatorname{dogs}$ would be equally disastrous for the progress of surgery. The fundamental advances made during the last twenty years, which have proved of such inestimable value not only in civil practice, but also during the war in the treatment of our wounded soldiers, were achieved in the first instance by means of experiments on dogs. By such experiments it was first shown to be possible to excise portions of the alimental canal, to make opexings from one part to the other in order to relieve obstruction, to remove part or the whole of the internal organs, to implant bone and tissues so as to restore defects, to deal fearlessly with the cavity of the chest, to sew up wounds in the living and beating heart, to restore continuity of wounded blood-vessels, and to perform many others of the feats which are the triumph of modern surgery.

Much more remains to be achieved in order to abolish or alleviate even a fraction of the pain and suffering which are all around us. But all activity in this direction would be hampered, and much of it brought to a standstill, if the Dogs' Protection Bill is allowed to become law.

Nor would the Bill diminish by one jot any pains at present suffered by dogs. Under the law as it at present stands, the infliction of pain on dogs is already prevented. According to the regulations now in force, the animal has to be under the full influence of an anæsthetic during the whole operation, and to be killed before recovering consciousness. Or, if the object of the experiment requires that the dog should be allowed to survive, it must be at once killed under an anæsthetic should pain supervene at any time after the operation.

These regulations can be justified on purely scientific grounds, since the existence of pain during an experiment is a disturbing factor, which is not only an unnecessary complication, but may also vitiate the whole result of the experiment. The only effect of the Bill, therefore, so far as dogs are concerned, would be thati a few more of the stray and homeless dogs that are now used for experiment would be added to the 20,000 or more which are killed by suffocation during each year at the Dogs' Home at Battersea.

We cannot believe the Government is so indifferent to the advancement of medical science and the human suffering which it aims at alleviating that such an act of folly as is contemplated in the Bill now under consideration will be permitted to be placed on the Statute Book because of the importunity of certain private members who disregard all that scientific knowledge of disease has to tell them. The Bill is down for the Report stage on May 23, and we look to Ministers to exert themselves sufficiently on that day to protect us from such a pernicious measure.

\section{SIR WILLIAM CROOKES, O.M., F.R.S.}

THE few remaining British men of science whose memories extend back to 1862 , in reviewing that long period of the past, never lose from the mental vision one remarkable figure. The occasion of the International Exhibition in that year afforded an opportunity by which a young English chemist sprang into sudden fame. The discovery of a new element, however remarkable its properties, would, perhaps, not have proved sufficient to rouse the interest of a mid-Victorian public, but the method of spectrum analysis used in its discovery being then new, coupled with the award of a medal to the exhibit, brought thallium and its discoverer very prominently into notice. The great scientific career thus begun nearly sixty years ago is now closed by the death of Sir William Crookes on Friday, April 4, not only full of years and honours, but also busy in the laboratory to the last.

Crookes was born on June 17,1832 . At an early age he entered as a student at the newly. instituted Royal College of Chemistry in Oxford Street, where he remained for some years under Hofmann as demonstrator and assistant. Here he found an atmosphere favourable to the development of his talent for investigation, but it is remarkable that the study of organic chemistry, the chief direction followed by Hofmann and his pupils, never seemed to attract him specially, and many years afterwards he was not ashamed to confess an almost entire ignorance of the work which had occupied so large a number of chemists, especially after Perkin's discovery of the dyes and the general adoption of Kekule's theory of benzene. His earliest paper records his discovery of the seleniocyanides in 1857 , and he was then occupied for a time by the developments then taking place in the processes of photography. The discovery of thallium by the application of the spectroscope gave him occupation for several years, but after completing the study of that element and its compounds it became evident that his preference lay in the direction of phenomena outside the range of ordinary chemical investigation, and that his researches would be pursued along no conventional lines. In passing, it ought to be mentioned that he was instrumental in securing the application of the powerful disinfectant properties of carbolic acid or phenol during the disastrous spread of the cattle plague in 1866.

Meanwhile, Crookes was hard at work on facts NO. 2580 , VOL. IO3] 
of his own discovery relating to attraction and repulsion accompanying radiation, and in 1873 he astonished the world by the invention of the radiometer. Probably no discovery within our time has given rise to more speculation or has led to a more remarkable development of ideas connected with radiation, and though Crookes did not furnish the true explanation of his instrument, he contributed a large number of experiments which assisted in its ultimate recognition.

From the phenomena shown by the radiometer was an easy step to the study of electrical discharges in high vacua, and henceforward his work on what he called "radiant matter" furnished the starting-point for many of the famous discoveries by others which have led to a completely new field of physics and an utterly novel view of the ultimate constitution of matter. Crookes's study of the rays from the cathode in a vacuum tube in which the gas was rarefied beyond a certain limit led him to consider that the flying particles represented an ultra-gaseous condition which he regarded as a fourth state of matter. This view, which at the time was rather unfavourably received, has been completely justified by further investigations, though his idea of the mass of the radiant particles has had to be modified.

About $188_{5}$ Crookes became interested in the phosphorescent spectra of solid bodies, and especially in those of the so-called rare earths. This led him to engage in very lengthy series of experiments on fractionation, and attempts at the resolution of mixtures of these substances into their constituents, and so he was led into the conception of what he called meta-elements. He supposed that some oxides, like yttria, might consist of molecules so nearly alike in properties and mass as to be indistinguishable from one another, and inseparable by any known process. Accordingly, these substances were represented in the periodic scheme of the elements as clustering into groups near to certain values of atomic weights. Crookes also devised a spiral model which has become very familiar for displaying the relations of the elements to atomic weight in connection with the periodic law and for illustrating his own views as to the "genesis of the elements." The definition of the term "element" in chemistry, and the characterisation of the recognised elements, formed the subject of his two presidential addresses to the Chemical Society in 1888 and 1889 .

During the subsequent thirty years of his life Crookes was much occupied with further experimental work on questions cognate to these subjects. His familiarity with spectroscopy enabled him to pursue successfully an inquiry into the preparation of eye-preserving glass for spectacles, the results of which were published in the Philosophical Transactions so recently as I9I4, and have led to valuable practical results, especially in the case of workers in glass and others exposed to furnace glare. The primary object was to find a glass which will cut off as much as possible of the heat radiation, but the experiments were extended to the search for glasses opaque to the ultraviolet. More than three hundred different glasses were investigated, and the compositions of nineteen which have been proved useful are given in the memoir.

It would be impossible in the short space at our disposal now to complete the list of Sir William Crookes's various spheres of activity, but mention must not be omitted of some of his publications. In 1859 he started the Chemical News, of which he continued to be proprietor and editor to the end of his life. His famous British Association address at Bristol in I899 on "The Wheat Problem" attracted for many years considerable attention from economists and agriculturists, and his visits to "South Africa in 1896 and in 1905 led to the publication of a small work on diamonds, which has had a large circulation. To these may be added the volume entitled "Select Methods in Chemical Analysis," which is full of useful information, and has passed through four editions, as well as several other books of a technical character.

Crookes was a man of extraordinary genius and immense physical activity, of which his copious published work is evidence. A man of his temperament and his remarkable independence of view in regard to the range of scientific inquiry and the proper attitude of the scientific investigator would naturally be led to look attentively at subjects of all kinds, some of which might be regarded as suspect by other people. It is, of course, well known that he took part in many inquiries concerning psychic phenomena, and that he published a book on spiritualism, in which he recorded certain experiences of his own. These, however, are subjects on which there is too much difference of sentiment and of opinion to be further considered now; they must be left to be handled by the biographer. All that the scientific world now feels is that it has lost a gieat pioneer worker in the field of natural knowledge.

It is needless to add that honours of all kinds fell thick on Crookes. He was elected into the Royal Society in I863, and the Royal, the Davy, and the Copley medals were awarded to him by the society, of which he finally became president. $\mathrm{He}$ also served as president of several other societies, including the Chemical Society, the British Association, and the Institution of Electrical Engineers. He received a gold medal and a prize of 6000 francs from the French Academy of Sciences in 1880 , and in 1899 the Albert medal of the Royal Society of Arts was awarded to him. The Order of Merit was conferred on him in Igro.

It may be of interest to some readers of NATURE to be reminded that in the series of "Scientific Worthies" issued by this journal was published on November 7,1907 , an appreciation of Crookes's scientific work from the pen of a distinguished physicist, Prof. P. Zeeman, of Amsterdam, which affords an estimate of the value of his work by a highly competent authority. W. A. T. 